\title{
A Brief Report on the Actions towards the Introduction of BIM in the Macedonian Construction Sector ${ }^{+}$
}

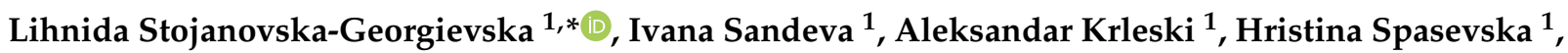 \\ Margarita Ginovska ${ }^{1}$, Igor Panchevski ${ }^{1,2}{ }^{,}$Risto Ivanov ${ }^{2}$, Ignasi Perez Arnal ${ }^{3}$, Tomo Cerovsek ${ }^{4}$ \\ and Tomas Funtik ${ }^{5}$ (D)
}

1 Faculty of Electrical Engineering and Information Technologies, Ss. Cyril and Methodius University, Rugjer Boskovic 18, 1000 Skopje, North Macedonia; ivana@feit.ukim.edu.mk (I.S.);

krleski@feit.ukim.edu.mk (A.K.); hristina@feit.ukim.edu.mk (H.S.); gmarga@feit.ukim.edu.mk (M.G.); igor.pancevski@gmail.com (I.P.)

2 Kreacija Association of Business and Consultants Skopje, Nikola Parapunov 41, 1000 Skopje, North Macedonia; voznes8@gmail.com

3 BIM Academy, WITS Institute SLU, Calle de Mallorca 346, 08013 Barcelona, Spain; ignasiperezarnal@bimacademy.es

4 Faculty of Civil and Geodetic Engineering, University of Ljubljana, Kongresni trg 12, 1000 Ljubljana, Slovenia; tomo.cerovsek@fgg.uni-lj.si

5 Faculty of Civil Engineering, Slovak University of Technology in Bratislava, Radlinského 11, 81005 Bratislava, Slovakia; tomas.funtik@stuba.sk

* Correspondence: lihnida@feit.ukim.edu.mk

† Presented at the Sustainable Places 2021, Rome, Italy, 29 September-1 October 2021.

Citation: Stojanovska-Georgievska, L.; Sandeva, I.; Krleski, A.; Spasevska, H.; Ginovska, M.; Panchevski, I.; Ivanov, R.; Arnal, I.P.; Cerovsek, T.; Funtik, T. A Brief Report on the Actions towards the Introduction of BIM in the Macedonian Construction Sector. Environ. Sci. Proc. 2021, 11, 8. https://doi.org/10.3390/ environsciproc2021011008

Academic Editor: Zia Lennard

Published: 24 November 2021

Publisher's Note: MDPI stays neutral with regard to jurisdictional claims in published maps and institutional affiliations.

Copyright: (c) 2021 by the authors. Licensee MDPI, Basel, Switzerland. This article is an open access article distributed under the terms and conditions of the Creative Commons Attribution (CC BY) license (https:/ / creativecommons.org/licenses/by/ $4.0 /)$.
Abstract: Although the building sector builds and renovates objects, the construction industry is currently due for a digital renovation. In this paper, we provide insight into the status of BIM adoption in North Macedonia as a step towards the digital transformation of the construction industry. The presented review on the current stage of development, benefits, and barriers is followed with showcasing the possibilities for using BIM for the assessment of the energy performance of buildings through case studies. Furthermore, the results of the conducted survey on BIM awareness and the proposed national roadmap for BIM adoption are elaborated on.

Keywords: digitalization; BIM; construction; productivity; energy performance; BIM roadmap

\section{Introduction}

The construction industry is an integral part of the global economy. Engineering and construction $(\mathrm{E} \& \mathrm{C})$ activities (the core part of the industry) generate approximately $\$ 10$ trillion in annual revenue, which equates to approximately $6 \%$ of global GDP. In recent years, however, the industry is failing to keep up with productivity gains made in other industries [1]. Project efficiencies, safety concerns, and low labor productivity are the challenges provoked by the industry's sluggish adoption of new technologies. Digitalization has the potential to change this situation. However, the construction industry continues to operate as it has for the past 50 years and remains the least digitized sector (apart from agriculture) [2]. To keep pace with innovation and to be more productive, the infrastructure and urban development (IU) industry must embrace digitalization. Building information modeling (BIM) is an important first step towards that [3]. The implementation of BIM in construction is a moment of digitization and will bring $13-21 \%$ savings in the design and implementation phase and $10-17 \%$ in operation and maintenance within the global infrastructure market by 2025 [4].

\section{Global Status of BIM Adoption}

BIM adoption has significantly increased around the globe in recent years, particularly in developed countries. The United States is one of the pioneers in BIM development and 
adoption in the construction industry, starting in 2003 by launching the "National 3D-4D program" for gradual implementation of 3D, 4D, and BIM for all major public projects.

First European legislative incentives towards BIM were released in 2014 with the European Commission directive 2014/24/EU, which recommends member states to use specific electronic tools such as BIM for public works contracts and design contests (European Parliament, 2014). The UK is widely perceived to be a global leader in the adoption of BIM technology, already moving toward BIM level 3. The Scandinavian countries are at the forefront in BIM adoption, the Netherlands has mandated the use of BIM for public projects, and in Germany, France, Brazil, and Austria BIM is gaining wide adoption [5].

The introduction of BIM has positively placed BIM standards as European standards. In parallel, there are local standards at national levels that sometimes differentiate from standards at the European level in order to better reflect the national construction industry [6-8].

\section{BIM Status in the Republic of North Macedonia}

In order to weigh the adoption and acceptance of BIM practice in North Macedonia, a survey on the Macedonian level of awareness, knowledge, and experience with BIM practice was carried out [9].

Since BIM aims to induce changes in both the public and private sectors in designing, problem solving, and building better projects faster and at fewer costs, the respondents were from 3 main sectors: AEC, public, and university. As a result, most of the total 312 respondents belong to the AEC (architecture, engineering, and construction) sector, with over $79 \%$, or 248 respondents; the public sector is represented with 53 respondents, or $17 \%$, and the university sector with 11 respondents, or $4 \%$.

Survey results provide a clear picture of where focus should be placed for the successful introduction and acceptance of BIM practice. The three major barriers detected through the survey are:

1. Lack of BIM trainings ( $33 \%$ or 103 respondents)

2. Insufficient requests from the clients (no demand for BIM design) (21.2\% or 66 respondents)

3. Missing standards and guidelines ( $15.4 \%$ or 48 respondents)

The survey on the adoption and acceptance of BIM practice shows that those most concerned about BIM software tools are architects and engineers for the purpose of design. Half of the respondents had heard of BIM software tools but only $2.5 \%$ were fully focused on delivering all of their designs in BIM. Most of these architects and engineers had educated themselves through their own initiative, generally on the two commercial software tools Graphisoft ArchiCAD and Autodesk Revit. No open BIM tools or other alternatives were known to most of the respondents. The basics of BIM processes and methodology, and BIM benefits for all construction phases are not accounted for in this study, and only one training curriculum exists in North Macedonia. The low or non-existing demand results in BIM trainees themselves being resistant and reluctant to learn new tools and workflows, as this is perceived as not useful and as a hindrance to their productivity. The biggest challenges are increasing the diversity of BIM training options and enlarging the demand, which will lead to the higher adoption of BIM in the private sector, potentially leading to its implementation in the public sector and national legislation.

\section{The Value of BIM in Achieving Energy Efficiency in Construction}

In order to overcome the identified barriers, a set of measures were implemented by the H2020 project TRAINEE https: / / trainee-mk.eu/en/ (accessed on 28 October 2021):

- Wide public promotion of BIM

- Development of 4 qualification schemes for BIM and organization of pilot trainings

- Drafting a document providing information on the step-by-step introduction of BIM into the national construction industry 
However, the strongest promotional impact demonstrates the benefits of using BIM tools by piloting the use of BIM software to show the potential of BIM to reduce the energy performance gap of new buildings as projected after the construction phase and the gap between the designed and actual energy performance of buildings [9]. Embedding the joint BIM-BEM process offers multiple iterations towards an optimized design in a shared environment. There are three different methods for integrating BIM and BEM procedures [10]:

- Combined: performed by combining the BIM model and BEM sub-model, where both are completed using one tool.

- Central: using a shared environment for both procedures, where the readability of specific data is ensured by an interoperability gateway, such as IFC format.

- Distributed: performed by transferring data between the design tool and simulation tools via a middleware.

Most preferable among them, according to the literature review and confirmed with the records of executed projects, is the central method. It corresponds to the chosen approach in the TRAINEE project in order to express the benefits of BIM towards energy efficiency in buildings. We took advantage of the use of BIM software tools such as Edificius and TerMus BIM ONE, as well as SolariusPV for photovoltaic systems design, provided by the Italian brand for software developing, ACCA [11,12].

Case studies were performed as six-phase activities on two different concepts of buildings: block housing and single (individual) housing.

- Phase 1 is based on selecting the housing block or the new design of a single house.

- $\quad$ Phase 2 considers the existing conditions of the physical context.

- Phase 3 is based on the calculation of solar irradiation from weather data.

- Phase 4 configures the automated drawing of the single-line electrical diagram of the photovoltaic installations.

- Phase 5 explores the tracking of consumption.

- Phase 6 fixes the energy savings and money flow control.

These case studies show the usability of BIM in performing energy modeling of existing buildings. It was shown that when the building is not initially constructed with a BIM, converting the existing building data into a model can serve to model future building performance and select retrofitting interventions which will justify the cost-gain ratio.

\section{Proposal for National Roadmap for Implementation of BIM}

The roadmap proposes strategies to overcome identified barriers and define the pathway to ensure a successful digital transition. The greatest challenges as identified in the BIM survey are:

- $\quad$ Lack of demand

- Lack of BIM skills (both trainings and skilled professionals)

- No existing national BIM standards and protocols

- Missing culture of collaborative projects

The actions proposed to achieve the step-by-step introduction of BIM on the national level are distributed by types of action that correspond to WEF's proposed types of action for BIM adoption. These types of actions can be distinguished into two groups: passive measures (including raising BIM awareness), which do not lead to the initialization of the implementation of BIM but rather act as prerequisites to start with the implementation of proactive measures, which occasionally result in systematic approaches, ensuring positive output, through motivation, collaboration, and enablement.

The set of measures that were proposed in the national Roadmap for implementation of $\mathrm{BIM}$, correspond to previously identified actions according to WEF and they spread through all four fields of action (leadership, standards, education and training, procurement). This approach is chosenin order to guaranty an in-depth adoption in all relevant spheres, and to ensure a stable foundation for transitioning from traditional to digital construction. 
The proposed roadmap for BIM adoption aims to draw the attention of relevant public and governmental authorities to be more proactive toward pushing the digitization of the national construction sector. Based on the experience of developed countries that are successful in the implementation of BIM and are harvesting its benefits after the phases of "initiated implementation", general recommendations which ensure the success of the adoption of BIM are:

- Introducing a BIM mandate is shown as a successful incentive.

- Providing a clear framework for procurement of BIM in construction projects in the public sector.

- Identifying a champion for BIM as a focal point to support its adoption.

\section{Conclusions}

BIM is changing the construction industry by changing its perspectives, its standard procedures, and its traditional ways of functioning. But BIM brings its own potential to harvest benefits in all stages of the project life cycle. Transformation towards BIM as a new technology and methodology for executing the construction in all phases of buildings requires a strategic plan. In order to achieve BIM's full adoption, its enforcement by the government is needed. At the early stages of its implementation, BIM's enforcement by the government as a driver for the construction of projects is necessary. Showcasing successful examples, promoting its benefits, and changing the culture of traditional construction are only some of the measures that will guarantee a change of perception and an embracement of its positive changes.

Author Contributions: This is a joint research article with individual contributions of the authors as follows. Conceptualization, L.S.-G. and H.S.; methodology, L.S.-G., I.P., T.C. and T.F.; software, I.P.A.; formal analysis and resources, L.S.-G., M.G., I.S., R.I., I.P. and A.K.; writing-original draft preparation, L.S.-G.; writing-review and editing, L.S.-G., I.P., R.I., T.C. and T.F. All authors have read and agreed to the published version of the manuscript.

Funding: This research was funded by the project 785005-TRAINEE-H2020-EE-2016-2017/H2020-EE2017-CSA-PPI, and the conference presentation at SP2021 was supported by the project 101033743 SEEtheSkills-H2020-LC-SC3-2018-2019-2020/H2020-LC-SC3-EE-2020-2.

Data Availability Statement: Publicly available datasets were analyzed in this study. This data can be found here: (http://trainee-mk.eu/images/TRAINEE/Deliverables/D3.1_Survey_about_ penetration_and_acceptance_of_BIM_practice_TRAINEE.pdf, accessed on 19 November 2021).

Conflicts of Interest: The authors declare no conflict of interest.

\section{References}

1. Barbosa, F.; Woetzel, J.; Srdhar, M.; Parsons, M.; Bertram, N.; Brown, S.; Mischke, J.; Ribeirinho, M. Reinventing Construction: A Route to Higher Productivity; McKinsey Global Institute: New York, NY, USA, 2017.

2. Alreshidi, E.; Mourshed, M.; Rezgui, Y. Requirements for cloud-based BIM governance solutions to facilitate team collaboration in construction projects. Requir. Eng. 2018, 23, 1-31. [CrossRef]

3. Almeida, P.R.; Solas, M.Z.; Renz, A.; Bühler, M.M.; Gerbert, P.; Castagnino, S.; Rothballer, C. Shaping the Future of Construction: A Breakthrough in Mindset and Technology; World Economic Forum: Geneva, Switzerland, 2016. [CrossRef]

4. Burgess, G.; Jones, M.; Muir, K. BIM in the UK House Building Industry: Opportunities and Barriers to Adoption; University of Cambridge: Cambridge, UK, 2018.

5. McAuley, B.; Hore, A.; West, R. BICP Global BIM Study—Lessons for Ireland's BIM Programme; Construction IT Alliance (CitA) Limited: Dublin, Ireland, 2017. [CrossRef]

6. NBC: Roadmap to Digital Transition for Ireland's Construction Industry 2018-2021. 2017. Available online: https://issuu.com/ constructionitalliance/docs/nbc_roadmap_to_digital_transition_updated_2020 (accessed on 19 November 2021).

7. Elagiry, M.; Marino, V.; Lasarte, N.; Elguezabal, P.; Messervey, T. BIM4Ren: Barriers to BIM Implementation in Renovation Processes in the Italian Market. Buildings 2019, 9, 200. [CrossRef]

8. Lee, G.; Borrmann, A. BIM policy and management. Constr. Manag. Econ. 2020, 38, 413-419. [CrossRef]

9. Stojanovska-Georgievska, L.; Spasevska, H.; Ivanov, R. Beyond the numbers-Result oriented report of the project TRAINEE. Zenodo 2020. [CrossRef] 
10. European Construction Sector Observatory. BIM in the EU Construction Sector. 2019. Available online: https:/ / ec.europa.eu / growth/sectors / construction/observatory/trend-papers_en (accessed on 19 October 2021).

11. Cerovsek, T. A review and outlook for a 'Building Information Model' (BIM): A multi-standpoint framework for technological development. Adv. Eng. Inform. 2011, 25, 224-244. [CrossRef]

12. Carvalho, J.P.; Almeida, M.; Bragança, L.; Mateus, R. BIM-Based Energy Analysis and Sustainability Assessment-Application to Portuguese Buildings. Buildings 2021, 11, 246. [CrossRef] 